УДК $811.112 .2 ` 255.2$

\author{
ФУНКЦИОНАЛЬНО-СЕМАНТИЧЕСКИЕ ОСОБЕННОСТИ \\ ПРИЛАГАТЕЛЬНЫХ СО ЗНАЧЕНИЕМ ИНТЕЛЛЕКТУАЛЬНОЙ \\ ДЕЯТЕЛЬНОСТИ (НА МАТЕРИЛАЕ РОМАНОВ Г. ГЕССЕ \\ И ИХ ПЕРЕВОДОВ НА РУССКИЙ ЯЗЫК)
}

\author{
(C) Луиза Гиматова
}

\title{
FUNCTIONAL AND SEMANTIC PECULIARITIES OF ADJECTIVES WITH THE MEANING OF INTELLECTUAL ACTIVITY (BASED ON H. HESSE'S NOVELS AND THEIR TRANSLATIONS INTO RUSSIAN)
}

\section{Luiza Gimatova}

\begin{abstract}
This paper explores semantic aspects of functioning of a lexical-semantic group of adjectives with the meaning of intellectual activity within the context of Hermann Hesse's works and their translations into Russian. The relevance of the study is determined by the lack of Russian linguistic studies, devoted to the analysis of attributive vocabulary based on the latest novels of an outstanding German-Swiss writer of the mid- $20^{\text {th }}$ century. These works are generally described as philosophical and intellectual prose. By means of comparative and contextual analysis, we studied lexical and grammatical features of the Russian translations of this lexicon to demonstrate the diversity of H. Hesse's linguistic and artistic view of the world. The methods of component analysis and structural classification of adjectives enabled us to identify common and distinguishing features of the considered lexical-semantic group. The latter were structured according to their gradual type between the two extremes: "being intelligent" and "being unintelligent (stupid)". The lexical semantics of the five subgroups reveals both commonly used meanings and the meanings of individual author's interpretations. The latter add to the writer's novels a certain "Hessian" individuality and uniqueness, which is especially appreciable in the Russian translations of these lexemes.
\end{abstract}

Keywords: lexical-semantic group, adjectival vocabulary, adjectival-substantive syntagma, H. Hesse, individual author's interpretation.

В статье исследуются семантические аспекты функционирования лексико-семантической группы прилагательных со значением интеллектуальной деятельности в рамках контекстов произведений Германа Гессе и их переводов на русский язык. Актуальность исследования обусловлена отсутствием отечественных работ, посвященных анализу атрибутивной лексики на примерах из поздних романов выдающегося немецко-швейцарского писателя середины XX века, которые общепринято характеризуют как философско-интеллектуальную прозу. При помощи методов сравнительно-сопоставительного и контекстуального анализов были исследованы некоторые лексикограмматические особенности перевода прилагательных со значением интеллектуальной деятельности на русский язык, демонстрирующие русскоязычному читателю многообразие языковой и художественной картины мира Г. Гессе. Методы компонентного анализа и структурной классификации прилагательных помогли выявить общие и дифференциальные признаки рассмотренной лексико-семантической группы. Последние были структурированы по градуальному типу в пределах двух полюсных признаков: «наличие ума» и «его полное отсутствие». Лексемы всех пяти подгрупп выявили в своей семантике как значения общеупотребительного характера, так и значения индивидуально-авторских интерпретаций. Последние придают романам писателя некую «гессеновскую» неповторимость, уникальность, которые в первую очередь можно ощутить в переводах данных лексем на русский язык.

Ключевые слова: лексико-семантическая группа, адъективная лексика, адъективносубстантивная синтагма, Г. Гессе, индивидуально-авторская интерпретация.

Интеллектуальная человеческая деятельность находит свое отражение в семантике большого количества лексических единиц, являющихся объектом исследовательского интереса ученыхлингвистов. Так, например, изучаются и подвергаются классификации глаголы интеллектуаль- 
ной деятельности [Кондратенко], фразеологизмы, выражающие признаки интеллекта в русском языке [Соколова], качественные прилагательные, характеризующие интеллект человека в русской и английской лингвокультурах [Инешина]. А. Н. Шрамм в предложенной им классификации качественных прилагательных также отдельным лексико-семантическим вариантом выделяет разряд рациональных прилагательных, обозначающих интеллектуальные состояния человека [Шрамм, c. 35]. Из перечисленного ряда примеров исследований наибольший интерес вызывают те работы, которые посвящены имени прилагательному, являющемуся наиболее сложной и при этом наименее изученной частью речи в силу его специфичной способности подстраиваться под семантику любого имени существительного и приобретать новые, метафорические значения.

Все вышесказанное говорит в пользу актуальности цели приводимого далее исследования, в котором представлена попытка изучить семантические аспекты функционирования лексикосемантической группы прилагательных со значением интеллектуальной деятельности в рамках контекстов произведений известного немецкошвейцарского писателя Германа Гессе. Прилагательные уже изучались в языке художественных произведений, в частности в языке произведений русских писателей [Ерофеева, Сафонова], однако не были выявлены отечественные работы, посвященные анализу атрибутивной лексики в произведениях Г. Гессе, которые принято характеризовать как философско-интеллектуальную прозу. В них прилагательные со значением интеллектуальной деятельности получают особую интерпретацию. Помимо выявления семантических аспектов их функционирования, целью данной работы является также попытка проанализировать некоторые лексико-грамматические особенности способов их перевода на русский язык.

В рамках исследования под лексикосемантической группой (ЛСГ) нужно понимать гораздо меньшее по объему в сравнении с семантическим полем объединение слов одной части речи, имеющих объединяющие их между собой семантические связи и отношения. А. Н. Шрамм указывает на то, что ЛСГ является одной из структурных разновидностей парадигм, отличающейся отношениями антонимического и синонимически-градационного характера [Шрамм, c. 44].

Применение методики компонентного анализа позволяет выделить в анализируемой ЛСГ общий семантический признак «отличающийся наличием умений и способностей к занятию интеллектуальной деятельностью». Для выделения дифференциальных признаков рациональным будет обратиться к работе Т. В. Леонтьевой, посвященной анализу и определению границ лексико-семантического поля «Интеллект» на материале русского языка [Леонтьева, с. 15].

При помощи метода сплошной выборки и расположения лексем упомянутого поля в соответствии с категориально-грамматическими семами автор выделяет лексико-семантическую группу слов с категориально-грамматической семой «признак». Классификацию лексем этой группы можно взять за основу для отбора прилагательных с соответствующими семами из оригинальных текстов поздних крупных произведений Германа Гессе («Степной волк» (1927) и «Игра в бисер» (1931-1942).

В соответствии с предложенной классификацией [Там же] в романах выявляются три подгруппы семантически сходных прилагательных, обозначающих три признака.

Первая подгруппа включает в себя лексикосемантические варианты качественных прилагательных со значением «интеллектуальнополноценный, способный мыслить»: intellektuell - 'интеллектуальный', klug - 'умный', gescheit 'смышленый', geistvoll - 'остроумный', geistig 'умственный', geistreich - 'остроумный', scharfsinnig - 'проницательный', bedächtig - 'рассудительный', weis - 'мудрый', vernünftig - 'разумный'. Объем обозначенной подгруппы увеличивается за счет включения в нее сложных прилагательных с дефисным написанием: intellektuellästhetisch - 'интеллектуально-эстетический', geistig-künstlerisch - 'умственно-искусственный', asketisch-geistig - 'аскетично-духовный'.

Обладая семантически устойчивой тенденцией активно сочетаться с одушевленными именами существительными, прилагательные данной подгруппы, однако, встречаются в контексте романов Г. Гессе также и в составе таких адъективно-субстантивных синтагм, в которых имя существительное обладает категорией неодушевленности, как, например, die klugen weißen Finger 'умные белые пальцы', eine geistreiche Fertigkeit - 'остроумная техника / сноровка ума', die intellektuelle Redlichkeit - 'интеллектуальная честность', intellektuell-ästhetische Geistigkeiten - 'интеллектуально-эстетическая духовность', weise und magische Spiele - 'мудрые и магические игры / мудрые и волшебные игры', ein weises und elastisches Aussiebesystem - 'мудрая и гибкая система отсева / мудрая и гибкая система отбора' и т. д. Имеющиеся в примерах определения в виде однородных членов расширяют семантический объем ключевых имен прилагательных рассматриваемой группы за счет значений «белые», «эс- 
тетическая», «магические / волшебные», «гибкая» и позволяют качественнее обрисовать индивидуальную языковую систему Г. Гессе в вопросе его отношения к понятию интеллектуальности. Читателю становится очевидным желание автора наделять способностями к умственной деятельности не только живые существа, но и части человеческого тела, а также абстрактные понятия. При этом ассоциативная характеристика перечисленных однородных лексем придает существительным окраску возвышенности и неповторимости.

Вторая подгруппа объединяет лексикосемантические варианты качественных прилагательных с денотативной составляющей «интеллектуально-неполноценный»: dumm - 'глупый', verrückt - 'сумасшедший', närrisch - 'глупый / дурацкий', sinnlos - 'безумный / бессмысленный', irrsinnig - 'безумный'. Из приведенного ряда показательной становится лексема närrisch, так как в текстах перевода она получает реализацию в виде лексем, не заявленных в словарных источниках:

...geht beim Electus, (...), die Freiheit so weit, daß es viele gibt, welche ihr Leben lang nach eigener Wahl die entlegensten und oft fast $n \ddot{a} r r$ is $c h$ en Studien betreiben,... [Hesse, с. 104] (здесь и далее разрядка наша - Л. Г.). - ' ..., mo y electus'a, (...), свобода заходит так далеко, что множество людей всю жизнь занимается по собственному выбору самыми периферийными и часто почти неле пьми проблемами,... '[Гессе, 2017, с. 62]; Имеются многие студенты, которые по своей воле всю жизнь посвящают самым нем вы сли мым и даже сумасбродным занятиям, ...[Гесce, 1969, с. 92].

В первом случае переводчик, С. Апт, использует лексическую единицу нелепье, а во втором варианте перевода Д. Каравкина и Вс. Розанов употребляют уже два однородных адъектива немыслимые и сумасбродные. Все три лексемы отличаются от словарных переводов возвышенным стилем речи, что можно описать как характерный признак языка художественного произведения. Выбор прилагательных такого стиля помогает русскоязычному читателю почувствовать субъективное отношение автора к описываемому явлению. Оно проявляется в том, что писатель номинирует глупье / дурацякие (перевод анализируемых лексем, приводимый в немецко-русских словарях [Новый немецко-русский словарь, с. 246], [Немецко-русский словарь, с. 222]) занятия людей очень обтекаемо-вежливо и деликатно и не имеет намерения резко критиковать последних, что указывает на особые личностные качества Г. Гессе.
Несмотря на особый интеллигентный стиль повествования писателя, он также позволяет себе в своих произведениях использование разговорной лексики, что выявляется, в первую очередь, в примерах с использованием прямой речи главных героев: Ich bin ein Vieh, Mozart, ein dumme s böses Vieh, krank und verdorben, da haben Sie tausendmal recht [Гессе, 2008, с. 270]. - Я скотина, Моцарт, глупая, злая скотина, больная и испорченная, тут вы тысячу раз правы [Гессе, 2016, с. 277]. Так, главный герой романа «Степной волк», Гарри Галлер, ведя диалог с воображаемым Моцартом, называет себя «глупой скотиной». В авторской подаче негативная семантика лексемы глупьй усиливается за счет добавочных однородных членов (злой, больной, испорченныли) всей именной группы.

Дальнейший анализ прилагательных второй подгруппы также позволяет выявить показательные примеры их индивидуально-авторской интерпретации. Перечисленные в ряду второй подгруппы лексемы пересекаются с именами прилагательными первой подгруппы, с которыми при помощи отрицательного префикса un- они образуют следующие антонимические пары: geistig ungeistig, vernünftig - unvernünftig. Благодаря обозначенной антонимии, адъективы ungeistig 'неумственный / недуховный' $u$ unvernünftig 'безрассудный / неразумный' автоматически пополняют ряд лексических единиц второй подгруппы. Если выявленные антонимические пары можно обозначить как общеупотребительные для сознания носителей немецкого языка, то в следующем примере из романа «Степной волк» обнаруживает себя уже индивидуально-авторский взгляд на противопоставляемые отношения некоторых адъективных лексем двух вышеназванных подгрупп: Du bist so auf eine dumme Art gescheit, scheint mir, richtig wie ein Professor...[ Гесce, 2008, с.105]. - Tbl, мне кажется, как-то по-глупому рассудителен, совсем по-профессорски [Гессе, 2016, с. 113].

Будучи использованными в контексте предложения в единой синтагме, прилагательные dumm u gescheit оказывают влияние на свои первичные значения глупый и смылиленый. Лексема gescheit приобретает негативную коннотацию, распространяющуюся в результате семантических корреляций на другие члены предложения. В частности, в глазах читателя подвергается сомнению авторитетность людей, обладающих званием профессора. Наряду с оригинальным примером при переводе анализируемой синтагмы обращает на себя внимание изменение частеречной принадлежности лексических единиц и замена их синтаксической функции. Адъективу 
dumm, выполняющему в предложении функцию определения, в переводе соответствует наречие по-глупому с функцией обстоятельства. Наречие охотно используется переводчиком, так как способно корректнее передать особенности лексической единицы оригинала и усилить прагматический эффект предложения. Словосочетание по-глупому рассудителен представляет собой оксюморон, авторский стилистический нюанс, полностью обесценивающий позитивный смысл, заложенный в семантике слова рассудительный. Следовательно, именно в переводе на русский язык усиливается эффект ощущения нестандартности личности писателя.

Еще одним примером индивидуального стиля повествования является использование Г. Гессе в романе «Игра в бисер» сложного прилагательного с дефисным написанием sinnvoll-sinnlos. По утверждению О. А. Лаптевой, имена прилагательные такой модели стандартно характеризуются тавтологичностью обоих компонентов [Лаптева, с. 198], однако использованные в анализируемых лексических единицах компоненты представляют собой антонимическую пару и относятся к двум разным подгруппам дифференциальных признаков исследуемой ЛСГ.

Приведенные далее примеры демонстрируют употребление нетипичных адъективов в рамках контекста и два альтернативных варианта их переводов на русский язык: ... dieser sinnvollsinnlose Rundlauf von Meister und Schüler, ...[Hesse, c. 331]. - ... осмысленнобессмысленное коловращение учителя и ученика,...[Гессе, 2017, с. 199]. - ... этот бессмысленно-осмысленныц бег по кругу учителя и ученика, ...[Гессе, 1969, с. 225].

Переводчики, стремясь сохранить индивидуальный стиль авторской речи, выбирают в качестве переводных лексем русские сложные прилагательные с дефисным написанием, заменяя единодушно лишь первый компонент наречиями осмысленно и бессмысленно, что соответствует логике грамматики русского языка.

Третья намного меньшая по объему подгруппа включает в себя качественные прилагательные со значением «необразованный, несведущий»: ungebildet - 'необразованный', unwissend 'незнающий'. При взгляде на морфемный состав прилагательных данной подгруппы можно обнаружить одинаковый для обеих лексем отрицательный префикс un-, широко развитый у адъективной лексики немецкого языка. Для передачи таких морфологических особенностей в переводном языке были подобраны соответствия, в морфемной структуре которых используется единственно возможная в данном случае при- ставка не-. В процессе отбора адъективной лексики со значением третьей подгруппы в тексте романа «Игра в бисер» между тем обнаружило себя субстантивированное прилагательное Ungelehrte, которое в разных текстах перевода вполне ожидаемо получает в качестве русских соответствий существительные профан и неуч. Здесь следует отметить, что процесс субстантивации открывает выявленной лексеме возможность самостоятельного употребления в речи и обладания своим собственным экстенсионалом. Наличие последнего, по словам Л. Теньера, отличает существительное от прилагательного [Tesniere, с. 68]. Следовательно, субстантивированное прилагательное Ungelehrte не может быть отнесено ни к одной из вышеназванных подгрупп прилагательных в силу отсутствия схожих с ними характеристик. Однако сама семантика данной лексической единицы позволяет вычленить в тексте произведения противопоставляемое ей по антонимическому признаку прилагательное gelehrt - 'ученый / образованный'. Оно содержит новый дифференциальный признак «образованный» и может быть добавлено в приводимую классификацию в виде четвертой подгруппы. Объем четвертой подгруппы может быть пополнен также путем отбора в текстах романов адъективной лексики, вступающей так же, как и лексема gelehrt, в антонимические связи с прилагательными третьей подгруппы: ungebildet - gebildet - 'образованный' и unwissend - wissend 'знающий'. Добавленные лексические единицы использованы в тексте анализируемых произведений как в виде сложного прилагательного с дефисным написанием (ihr gelehrt-artistisches Dasein - 'учено-артистическая жизнь'), так и с усилительными частицами all - 'весь' и viel 'много', оправдывающими свое употребление в контексте заданных адъективно-субстантивных синтагм (allwissende blaue Augen - 'всезнающие синие глаза', die klugen Monologe des vielwissenden Pilgers - 'умные монологи всезнающего паломника').

В процессе изучения синтагматического окружения лексемы gelehrt в разных фрагментах романа «Степной волк» обращает на себя внимание ее использование в сочетании с отрицательной частицей nicht - 'не': Ein großer Teil der Bücher jedoch war nicht gelehrten Inhalts, die große Mehrzahl waren Werke der Dichter aus allen Zeiten und Völkern [Гессе, 2008, с. 15]. - Однако изрядная часть книг была не ученого содержания, подавляющее большинство составляли сочинения писателей всех времен и народов [Гесce, 2016, c. 15]. 
Благодаря образованной таким способом отрицательной семантике рассматриваемое прилагательное оказывает на читателя стилистически обоснованный эффект неожиданности от необычного противопоставления и автоматически пополняет состав третьей подгруппы лексем. Для сохранения описанного эффекта переводчик использует аналогичную отрицательную конструкцию русского языка - отрицательную частицу не в сочетании с прилагательным.

Однако, несмотря на желание переводчика сохранить индивидуальные характеристики стиля автора художественного произведения, явление соответствий грамматических конструкций с использованием прилагательных исследуемой ЛСГ не всегда возможно при их передаче на русский язык, что может быть продемонстрировано следующими примерами:

1. ... und mühsamer Selbstzucht ein neues, as $k$ et is ch-ge is tiges Leben und Ideal gebaut (...) hatte,...[Гессе, 2008, с. 85]. - ... и благодаря строгой самодисииплине, построил себе новую жизнь, основанную на аскетизме и духовности ...[Гессе, 2016, с. 85].

В приведенном в качестве примера предложении произведена замена сложного прилагательного описательной конструкцией, содержащей причастный оборот.

2. Vernünftig sprach ich mir selber zu, wie einem geängstigten Kind, ... [Гecce, 2008, c. 108]. Я уговаривал себя, как ребенка, разумными доводами ... [Гессе, 2016, с. 108].

Отнесенное нами к первой подгруппе прилагательное занимает в немецком предложении обособленную начальную позицию, где благодаря этому выполняет функцию обстоятельства образа действия и, согласно правилам немецкой грамматики, является наречием. В переводе рассматриваемая лексема получает вариантное соответствие в виде прилагательного разумный, выполняющего в предложении уже функцию определения.

Подобные отличия обусловлены особенностями грамматических структур немецкого и русского языков. Также причиной может послужить нежелание переводчика нарушать нормы и узус переводящего языка.

Отбор в рамках произведений Г. Гессе адъективных слов ЛСГ со значением «интеллектуальная деятельность» позволяет выявить пятую подгруппу прилагательных, семантические значения которых можно объединить признаком «интеллектуально-совершенный». Сюда мы относим прилагательные genial - 'гениальный' и begabt'одаренный'. В интерпретации Г. Гессе гениальными становятся не только люди мира науки (genialer Gelehrter - 'гениальный ученый'), но и те, о ком стандартно сложено совершенно далекое от заложенного в семантике прилагательного genial представление (der geniale Narr und Nihilist - 'гениальный чудак и нигилист'). Показательно также то, что прилагательные данной группы получают большое количество оценочных усилителей в виде hoch - 'высокий', при помощи которого образуется сложное прилагательное hochbe$g a b t$ - 'высокоодаренный', а также в виде форм превосходной степени: die begabtesten - 'самые талантливые', höchstbegabt - 'очень одаренный', die genialste Leistung des Menschentums - 'гениальное достижение человечества'. Данный факт говорит о том, что, будучи сам неординарной личностью, Г. Гессе тяготеет ко всему, что не вписывается в рамки привычного. По этой причине в словаре его языка данные лексемы получают такое словообразовательное многообразие.

Прилагательные всех пяти выявленных подгрупп могут быть структурированы по градуальному типу [Щипицына]. В данной работе целесообразным представляется структурировать подгруппы в пределах двух полюсных признаков, где один из них обозначает наличие ума, а другой - его полное отсутствие. Соответственно, можно предложить следующую структуру признаков проанализированной ЛСГ:

1) интеллектуально-совершенный;

2) интеллектуально-полноценный, способный мыслить;

3) образованный;

4) необразованный, несведущий;

5) интеллектуально-неполноценный.

Таким образом, проведенное исследование позволяет сделать следующие выводы. Фактический материал, состоящий из адъективной лексики, отобранной из наиболее поздних произведений Германа Гессе, был структурирован в рамках лексико-семантической группы с общим семантическим признаком «отличающийся наличием умений и способностей к занятию интеллектуальной деятельностью». Прилагательные были распределены по подгруппам с пятью выявленными дифференциальными признаками, демонстрирующими двухполюсную градацию. Подгруппы исследованно ЛСГ создают между собой антонимические пары, образованные путем добавления к одному из антонимов отрицательного префикса un-. Лексемы всех пяти подгрупп выявили в своей семантике как значения общеупотребительного характера, так и значения индивидуально-авторских интерпретаций. Последние придают романам писателя некую «гессеновскую» неповторимость, уникальность, которые можно ощутить в их переводах на русский 
язык. Так, Г. Гессе любит наделять интеллектуальными свойствами не только живые существа, но и части человеческого тела, а также абстрактные понятия. Субъективная оценка «гессеновских» прилагательных проявляется также в использовании им в рамках единой синтагмы адъективов с противопоставляемым значением: sinnvoll-sinnlos. Особые оценочные коннотации получают прилагательные с дифференциальным признаком «образованный» благодаря усилительным частицам all - 'весь' и viel - 'много' и формам превосходной степени. Те же оценочные усилители обнаруживаются у прилагательных с признаком «интеллектуально-совершенный». Писатель придает последним разные оттенки при помощи лексемы hoch - 'высокий' и опять же форм превосходной степени. В языковой картине мира Г. Гессе обнаруживает себя выстраивание в один ряд представлений о гениальности ученого и гениальности чудака.

Все вышесказанное говорит об особенном стиле интеллектуальной художественной прозы и о незаурядности и художественном таланте немецко-швейцарского писателя середины XX века.

\section{Список литературы}

Гессе Г. Степной Волк / Пер. с нем. С. Апта. Москва: Издательство АСТ, 2016. 283 с.

Гессе Г. Степной волк: Книга для чтения на немецком языке. СПб.: Антология, КАРО, 2008. 288 с.

Гессе Г. Игра в бисер / Пер. с нем. С. Апта. М.: ACT, 2017. 510,[2] c.

Гессе Г. Игра в бисер / Пер. с нем. Д. Каравкиной и Вс. Розанова. М.: Худож. лит., 1969. 542 с.

Ерофеева И. В., Сафонова С. Г. Репрезентация концепта «богатство» адъективными образованиями в языке произведений Ф. М. Достоевского // Филология и культура. Philology and Culture. 2017. № 1 (47) C.16-24.

Инешина Л. Г. Особенности качественных прилагательных, характеризующих интеллект человека, URL: https://multiurok.ru (дата обращения: 31.05.2019)

Кондратенко Л. И. Глаголы интеллектуальной деятельности (на примере текстов прозы И. С. Тургенева): автореф. дис. ...канд. филол. наук. Воронеж, 2005. $20 \mathrm{c}$

Лаптева О. А. О метафорических сложных «прилагательных с дефисом» в современном немецком языке // Вестник СПбГУ. 2008. Сер.9. 2008. Вып. 3. Ч. II. C. $195-200$.

Леонтьева T. В. Интеллект человека в русской языковой картине мира: моногр. Под ред. Е. Л. Березович. Екатеринбург: Изд-во ГОУ ВПО «Рос. гос. проф.-пед. ун-т», 2008, 280 с.

Немеико-русский словарь (под ред. А. И. Носова). Ростов н /Д.: Изд-во Рост. ун-та, 1995. 389 с.
Новый немеико-русский словарь, русско-немеикий словарь: 42000 слов. Киев: А.С.К., 2000. 808 с.

Соколова, М. А. Выражение признаков интеллекта фразеологизмами русского языка (на фоне испанского языка): автореф. дис. ... канд. филол. наук. СПб., 1995. $16 \mathrm{c}$.

Щипицына $Г$. М. Парадигматическая структура лексико-семантических групп имен прилагательных русского языка. URL: https://cyberleninka.ru/article/n/ paradigmaticheskaya-struktura-leksiko-semanticheskihgrupp-imyon-prilagatelnyh-russkogo-yazyka (дата обращения: 02.06.2019)

Шрамм А. Н. Очерки по семантике качественных прилагательных: на материале современного русского языка. Л.: Изд-во Ленингр. гос. ун-та, 1979. 134 с.

Hesse H. Das Glasperlenspiel: Versuch einer Lebensbeschreibung des Magister Ludi Josef Knecht samt Knechts hinterlassenen Schriften. Berlin: 2014. 920 S.

Tesniere L. Elements de syntaxe strukturale. Paris, Klincksieck, 1959. 670 p. (Процитировано по Воль $\phi$ E. M. Грамматика и семантика прилагательного. М.: Наука, 1978. 200 с.)

\section{References}

Gesse, G. (2016). Stepnoi Volk; per.s nem. S. Apta [Steppenwolf: A Novel. Translated by S. Apt]. 283 p. Moscow, izdatel'stvo AST. (In Russian)

Gesse, G. (2008). Stepnoi volk: Kniga dlia chteniia na nemetskom iazyke [Steppenwolf: A Book for Reading in German]. 288 p. St. Petersburg, Antologiia, KARO. (In German)

Gesse, G. (2017). Igra v biser / Per. s nem. S. Apta. [The Glass Bead Game. Translated by S. Apt]. 510, [2] p. Moscow, AST. (In Russian)

Gesse, G. (1969). Igra v biser/ Per. s nem. D. Karavkinoj $i$ Vs. Rozanova. [The Glass Bead Game. Translated by D. Karavkina and Vs. Rozanov]. 542 p. Moscow, Hudozh. lit. (In Russian)

Hesse, H. (2014). Das Glasperlenspiel: Versuch einer Lebensbeschreibung des Magister Ludi Josef Knecht samt Knechts hinterlassenen Schriften. [The Glass Bead Game: A Tentative Sketch of Magister Ludi Joseph Knecht's Life]. 920 p. Berlin. (In German)

Erofeeva, I. V., Safonova, S. G. (2017). Reprezentatsiia kontsepta "bogatstvo" adiektivnymi obrazovaniiami v iazyke proizvedenii F. M. Dostoevskogo [Representations of the Concept "Wealth" by Means of Adjectives in the Language of F. M. Dostoevsky's Works]. Filologiia i kultura Philology and Culture. No. 1 (47), pp. 16-24. (In Russian)

Ineshina, L. G. Osobennosti kachestvennyh prilagatel'nyh, harakterizujushhih intellekt cheloveka [Peculiarities of Qualitative Adjectives Characterizing Human Intellect]. URL: https://multiurok.ru (accessed: 31.05.2019). (In Russian)

Kondratenko, L. I. (2005).Glagoly intellektual'noj dejatel'nosti (na primere tekstov prozy I.S.Turgenea): avtoref. dis. ...kand. filol. nauk [Verbs of Intellectual Activity (based on I. S. Turgenev's prose texts): Doctoral Thesis Abstract]. Voronezh, 20 p. (In Russian) 
Lapteva, O. A. (2008). O metaforicheskih slozhnyh "prilagatel'nyh s defisom" $v$ sovremennom nemeckom jazyke [On the Methaphorical Compound Adjectives with a Hyphen in Modern German]. Vestnik Saint Petersburg State University. Ser. 9. Issue. 3. Ch. II, pp. 195-200. (In Russian)

Leont'eva, T. V. (2008). Intellekt cheloveka $v$ russkoi iazykovoi kartine mira: monogr. [Human Intellect in the Russian Linguistic World Image Text: A Monograph]. 280 p. Ekaterinburg, izd-vo GOU VPO "Ros. gos. prof. ped. un-t”. (In Russian)

Nemetsko-russkii slovar' (pod red. A. I. Nosova) (1995) [German-Russian Dictionary]. 389 p. Rostov na Donu, izd-vo Rost. un-ta. (In Russian, in German)

Novyi nemetsko-russkii slovar', russko-nemetskii slovar': 42000 slov (2000) [New German-Russian, Russian-German Dictionary]. 808 p. Kiev, A.S.K. (In Russian, in German)

Sokolova, M. A. (1995). Vyrazhenie priznakov intellekta frazeologizmami russkogo iazyka (na fone ispanskogo iazyka): avtoref. dis. ... kand. filol. nauk [Expressing Signs of Intellect by Means of Russian
Phraseologisms (based on the Spanish language): Doctoral Thesis Abstract]. Saint Petersburg, 16 p. (In Russian)

Shipitsyna, G. M. Paradigmaticheskaia struktura leksiko-semanticheskih grupp imen prilagatel'nyh russkogo iazyka [Paradigmatic Structure of LexicalSemantic Groups of Russian Adjectives]. URL: https://cyberleninka.ru/article/n/paradigmaticheskayastruktura-leksiko-semanticheskih-grupp-imyonprilagatelnyh-russkogo-yazyka (accessed 02.06.2019). (In Russian)

Shramm, A. N. (1979). Ocherki po semantike kachestvennyh prilagatel'nyh: na materiale sovremennogo russkogo jazyka. [Essays on the Semantics of Qualitative Adjectives in the Modern Russian Language]. 134 p. Leningrad, izd-vo Leningr. gos. un-ta. (In Russian)

Tesniere L. (1959). Elements de syntaxe strukturale. [Elements of Structural Syntax]. Paris. Cited by Vol'f, E. M. (1978). Grammatika $i$ semantika prilagatel'nogo. [Grammar and Semantics of Adjectives]. 200 p. Moscow, Nauka. (In Russian, in French)

The article was submitted on 16.06.2019 Поступила в редакцию 16.06.2019

\section{Gimatova Luiza Ilgizovna,} graduate student, Kazan Federal University, 18 Kremlyovskaya Str., Kazan, 420008, Russian Federation. gil.gim@mail.ru 